\title{
Evidence for two distinct phenotypes of chronic kidney disease in individuals with type 1 diabetes mellitus
}

\author{
Giuseppe Penno $^{1}$ - Eleonora Russo ${ }^{1} \cdot$ Monia Garofolo $^{1} \cdot$ Giuseppe Daniele $^{1}$. \\ Daniela Lucchesi $^{1}$ - Laura Giusti $^{1}$ - Veronica Sancho Bornez ${ }^{1}$. Cristina Bianchi ${ }^{1}$. \\ Angela Dardano ${ }^{1} \cdot$ Roberto Miccoli $^{1} \cdot$ Stefano Del Prato ${ }^{1}$
}

Received: 2 November 2016 / Accepted: 23 February 2017 /Published online: 29 March 2017

(C) Springer-Verlag Berlin Heidelberg 2017

\begin{abstract}
Aims/hypothesis In a retrospective, observational, crosssectional, single-centre study, we assessed the prevalence and correlates of different CKD phenotypes (with and without albuminuria) in a large cohort of patients of white ethnicity with type 1 diabetes.

Methods From 2001 to 2009, 408 men and 369 women with type 1 diabetes (age $40.2 \pm 11.7$ years, diabetes duration $19.4 \pm 12.2$ years, $\left.\mathrm{HbA}_{1 \mathrm{c}} 7.83 \pm 1.17 \%[62.0 \pm 12.9 \mathrm{mmol} / \mathrm{mol}]\right)$ were recruited consecutively. Albumin-to-creatinine ratio (ACR) and eGFR (Modification of Diet in Renal Disease) were obtained for all individuals, together with CKD stage. Diabetic retinopathy and peripheral polyneuropathy were detected in $41.5 \%$ and $8.1 \%$, respectively, and cardiovascular disease (CVD) occurred in $8.5 \%$. Adjudications of CKD phenotype were made by blinded investigators.

Results Normo- (ACR <3.4), micro- (ACR 3.4-34) or macroalbuminuria (ACR $\geq 34 \mathrm{mg} / \mathrm{mmol}$ ) were present in $91.6 \%, 6.4 \%$ and $1.9 \%$ of individuals, respectively. eGFR categories $1\left(\geq 90 \mathrm{ml} \mathrm{min}^{-1}[1.73 \mathrm{~m}]^{-2}\right), 2\left(60-89 \mathrm{ml} \mathrm{min}^{-1}\right.$ $\left.[1.73 \mathrm{~m}]^{-2}\right)$ and $3\left(<60 \mathrm{ml} \mathrm{min}^{-1}[1.73 \mathrm{~m}]^{-2}\right)$ were present in $57.3 \%, 39.0 \%$ and $3.7 \%$, respectively. The majority of participants had no CKD (89.4\%), while stages $1-2$ and $\geq 3$
\end{abstract}

Electronic supplementary material The online version of this article (doi:10.1007/s00125-017-4251-1) contains peer-reviewed but unedited supplementary material, which is available to authorised users.

Giuseppe Penno

pgiuse@immr.med.unipi.it

1 Diabetes and Metabolic Disease Section, Department of Clinical and Experimental Medicine, Azienda Ospedaliero-Universitaria Pisana, University of Pisa, 2 Via Paradisa, 56124 Pisa, Italy
CKD were detected in $6.8 \%$ and $3.7 \%$, respectively. The albuminuric $\left(\mathrm{Alb}^{+}\right)$and non-albuminuric $\left(\mathrm{Alb}^{-}\right)$phenotypes were present in $12(41.4 \%)$ and 17 (58.6\%) individuals with stage $\geq 3 \mathrm{CKD}$, respectively. Individuals with an ACR $<3.4 \mathrm{mg} / \mathrm{mmol}$ were subdivided into those with normal albuminuria $(<1.1 \mathrm{mg} / \mathrm{mmol} ; 77.2 \%)$ and mildly increased albuminuria $(1.1-3.4 \mathrm{mg} / \mathrm{mmol} ; 14.4 \%)$, and individuals with stage 2 CKD were subdivided into those with eGFR $75-89 \mathrm{ml} \mathrm{min}^{-1}[1.73 \mathrm{~m}]^{-2}$ and $60-74 \mathrm{ml} \mathrm{min}^{-1}[1.73 \mathrm{~m}]^{-2}$. ACR $<3.4 \mathrm{mg} / \mathrm{mmol}(88.7 \%)$ and even $<1.1 \mathrm{mg} / \mathrm{mmol}$ $(70.4 \%)$ were common in individuals with eGFR $60-74 \mathrm{ml} \mathrm{min}{ }^{-1}[1.73 \mathrm{~m}]^{-2}$. The prevalence of ACR $<1.1 \mathrm{mg} / \mathrm{mmol}$ was lower but still significant (34.5\%) in those with stage $\geq 3 \mathrm{CKD}$. In logistic regression analysis, stages $1-2$ and $\geq 3 \mathrm{CKD}$ were independently associated with age, $\mathrm{HbA}_{1 \mathrm{c}}$, $\gamma$-glutamyltransferase, fibrinogen, hypertension, but not with sex, BMI, smoking, HDL-cholesterol or triacylglycerol. Inclusion of advanced retinopathy removed $\mathrm{HbA}_{1 \mathrm{c}}$ from the model. The CKD Alb ${ }^{+}$phenotype correlated with diabetes duration, $\mathrm{HbA}_{1 \mathrm{c}}$, HDL-cholesterol, fibrinogen and

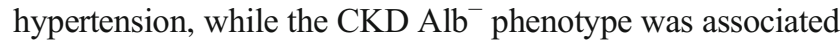
with age and hypertension, but not with diabetes duration, $\mathrm{HbA}_{1 \mathrm{c}}$ and fibrinogen.

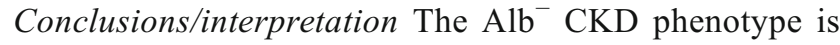
present in a significant proportion of individuals with type 1 diabetes supporting the hypothesis of two distinct pathways $\left(\mathrm{Alb}^{+}\right.$and $\left.\mathrm{Alb}^{-}\right)$of progression towards advanced kidney disease in type 1 diabetes. These are probably distinct pathways as suggested by different sets of covariates associated with the two CKD phenotypes.

Keywords Albuminuria $\cdot$ Chronic kidney disease $\cdot$ Diabetic retinopathy · Glomerular filtration rate · Type 1 diabetes mellitus 


$\begin{array}{ll}\text { Abbreviations } \\ \mathrm{ACR} & \text { Albumin-to-creatinine ratio } \\ \mathrm{Alb}^{+} & \text {Albuminuric (CKD phenotype) } \\ \mathrm{Alb}^{-} & \text {Non-albuminuric (CKD phenotype) } \\ \mathrm{ALT} & \text { Alanine aminotransferase } \\ \mathrm{AST} & \text { Aspartate aminotransferase } \\ \mathrm{CKD} & \text { Chronic kidney disease } \\ \mathrm{CVD} & \text { Cardiovascular disease } \\ \text { ERFD } & \text { Early renal function decline } \\ \mathrm{GGT} & \gamma \text {-glutamyltransferase } \\ \mathrm{RAS} & \text { Renin-angiotensin system } \\ \mathrm{UAE} & \text { Urinary albumin excretion }\end{array}$

\section{Introduction}

Chronic kidney disease (CKD) is a major complication of diabetes and an independent risk factor for cardiovascular disease (CVD). Albuminuria and reduced GFR are hallmarks of renal damage in individuals with diabetes [1]. In the progression of $\mathrm{CKD}$, albuminuria is commonly believed to precede GFR loss [2] with microalbuminuria being the earliest marker of renal damage $[2,3]$. Thus, urinary albumin excretion (UAE) is routinely measured during screening, diagnosis and management of diabetic nephropathy [4].

Recently, this view has been challenged $[5,6]$ following identification of individuals with type 2 diabetes who have non-albuminuric renal function impairment [7-11]. In the UK Prospective Diabetes Study (UKPDS), over a median follow-up of 15 years, about half of the participants who developed renal impairment had no prior albuminuria [12]. Data from the National Health and Nutrition Examination Survey (NHANES) [13] suggest a trend in the change of CKD phenotypes. While the rate of any CKD in individuals with diabetes has not changed over time, the prevalence of an albumin-to-creatinine ratio (ACR) $\geq 3.4 \mathrm{mg} / \mathrm{mmol}$ decreased from $20.8 \%$ in $1988-1994$ to $15.9 \%$ in $2009-2014$. In contrast, the prevalence of eGFR $<60 \mathrm{ml} \mathrm{min}^{-1}[1.73 \mathrm{~m}]^{-2}$ increased from $9.2 \%$ to $14.1 \%$.

Limited information is available concerning a similar heterogeneity in those with type 1 diabetes. GFR decline can occur with no increased albuminuria even in individuals with long-standing type 1 diabetes. A renal biopsy study of 105 normoalbuminuric individuals with type 1 diabetes of $\geq 10$ years duration showed advanced diabetic glomerular lesions even in those with mild GFR reduction (to $<90 \mathrm{ml} \mathrm{min}{ }^{-1}[1.73 \mathrm{~m}]^{-2}$ ) [14]. Over 19 years of the Diabetes Control and Complications Trials/Epidemiology of Diabetes Interventions and Complication (DCCT/EDIC), $11.4 \%$ of participants with type 1 diabetes developed sustained reduction of eGFR to $<60 \mathrm{ml} \mathrm{min}^{-1}[1.73 \mathrm{~m}]^{-2}$. Among these, 24\% developed persistent reduction in eGFR while remaining normoalbuminuric [15]. Thus, although AER was associated with eGFR decline in $76 \%$ of participants a sustained loss of eGFR could not be identified in $24 \%$ of cases.

Microalbuminuria was found to revert to normoalbuminuria in several studies of type 1 diabetes [16-18] suggesting that the appearance of microalbuminuria does not necessarily signal the start of the progression of diabetic nephropathy [18]. Rather, these findings support the concept of a non-albuminuric CKD phenotype where AER does not progress despite steadily declining GFR $[19,20]$. Interestingly, albuminuria and loss of GFR seem to be associated with distinct clusters of specific risk factors, suggesting that the two phenotypes only partly share common pathogenic mechanisms $[11,20]$.

Here, we report the results of a retrospective analysis performed in a large cohort of individuals with type 1 diabetes designed to determine the prevalence of CKD phenotypes (i.e. with and without albuminuria), describe associations with other diabetes complications and identify any differences in the associated factors.

\section{Methods}

Participants Type 1 diabetes was defined as diagnosis at $<36$ years with immediate insulin requirement and unbroken insulin need after the initial year since diagnosis [21]. All individuals with type 1 diabetes $(n=843)$ meeting those criteria who attended the diabetes unit of our institution from 1 January 2001 to 31 December 2009 for screening of complications were eligible for inclusion. Exclusion criteria included pregnancy, non-white ethnicity $(n=32,4.0 \%)$, diabetes duration $<1$ year $(n=34,4.0 \%)$ and dialysis or renal transplantation. A total of 777 individuals were recruited. The Ethics Committee of the University of Pisa approved the study and consent procedures. Written informed consent was obtained from each participating individual.

All participants underwent a structured interview collecting information about onset of diabetes, its duration, smoking and pharmacological treatments [21]. Body weight, height and waist circumference were measured. BP was measured after 5 min rest in a sitting position, and the average of two measurements (taken 5 min apart) was calculated; hypertension was defined for systolic BP >140 mmHg and/or diastolic BP $>80 \mathrm{mmHg}$ and/or use of antihypertensive medication(s). Blood was drawn once, on entry, after overnight fasting for determination of creatinine, $\mathrm{HbA}_{1 \mathrm{c}}$, lipids and other variables (see ESM Methods).

Measurements ACR was determined in at least three first-void urine samples obtained at about 1 month intervals in the year preceding recruitment. Urine samples $(n=175$, $6.7 \%$ ) with abnormal sediments (nitrites or $\geq 250$ leucocytes $/ \mathrm{ml}$ ) 
were discarded. Albumin and creatinine were assayed on the morning of collection.

$\mathrm{HbA}_{1 \mathrm{c}}$ was measured by HPLC using DCCT-aligned methods [22]. Triacylglycerol, total cholesterol and HDL-cholesterol were determined by enzymatic methods and LDL-cholesterol was calculated using the Friedewald formula [23]. Standard methods were employed for the measurement of the other variables (see ESM Methods).

Definition of renal outcomes Based on the geometric mean of three ACR values the following categories were defined: normoalbuminuria $(<3.4 \mathrm{mg} / \mathrm{mmol})$, microalbuminuria or moderately increased albuminuria $(3.4-34 \mathrm{mg} / \mathrm{mmol})$ and macroalbuminuria or severely increased albuminuria ( $\geq 34 \mathrm{mg} / \mathrm{mmol}$ ). Normoalbuminuria was subdivided into normal albuminuria $(<1.1 \mathrm{mg} / \mathrm{mmol})$ and mildly increased albuminuria (1.1-3.4 mg/mmol) (see ESM Methods).

eGFR was calculated by the Modification of Diet in Renal Disease (MDRD) Study equation [24] and the following categories were identified: category 1 , eGFR $\geq 90$; category 2 , eGFR 60-89; and category 3, eGFR $<60 \mathrm{ml}$ $\min ^{-1}[1.73 \mathrm{~m}]^{-2}$. Category 2 was subdivided into eGFR $75-89 \mathrm{ml} \mathrm{min}^{-1}[1.73 \mathrm{~m}]^{-2}$ and $60-74 \mathrm{ml} \mathrm{min}^{-1}[1.73 \mathrm{~m}]^{-2}$.

CKD was defined as: no CKD (eGFR $\geq 60 \mathrm{ml} \mathrm{min}^{-1}$ $[1.73 \mathrm{~m}]^{-2}$ and normoalbuminuria), stages $1-2 \mathrm{CKD}$ (eGFR $\geq 60 \mathrm{ml} \mathrm{min}^{-1}[1.73 \mathrm{~m}]^{-2}$ and albuminuria) and stages $\geq 3 \mathrm{CKD}$ (eGFR $<60 \mathrm{ml} \mathrm{min}^{-1}[1.73 \mathrm{~m}]^{-2}$ irrespective of albuminuria), according to the National Kidney Foundation's Kidney Disease Outcomes Quality Initiative [25]. CKD stages 3-5 were pooled.

Participants were further classified as having one of the following CKD phenotypes: albuminuria alone (stage 1-2 CKD), reduced eGFR alone (stage $\geq 3$ CKD without albuminuria, $\mathrm{Alb}^{-}$) or both albuminuria and reduced eGFR (stage $\geq 3 \mathrm{CKD}$ with albuminuria, $\mathrm{Alb}^{+}$).

Assessment of diabetes complications Diabetic retinopathy was assessed by retinal photography [21] and classified according to the Global Diabetic Retinopathy Project Group criteria [26] as non-advanced or advanced, sight-threatening retinopathy. Diabetic neuropathy was assessed with a validated questionnaire [27] and routine screening tests including vibration perception threshold [21]. The presence of previous CVD was determined based on a medical history of all documented major acute events. A 12 lead resting ECG was recorded and coded according to the Minnesota Code [28]. Peripheral vascular disease was assessed by search for femoral and foot pulses and measurement of ankle/brachial ratio (see ESM Methods).

Statistics For this analysis, we first stratified the study population according to AER or eGFR and then assessed the prevalence and implication of CKD stage for each combination of the two. Data are expressed as median (interquartile range [IQR]) and/or mean $\pm \mathrm{SD}$ for continuous variables, and number of cases and percentage for categorical variables. Continuous variables were compared by the Student's $t$ test or one-way ANOVA for normally distributed variables, and by the Wilcoxon Sum-of-Ranks (Mann-Whitney) $U$ test or Kruskall-Wallis test for variables with skewed distribution. Pearson $\chi^{2}$ or Fisher exact tests were applied to categories. For post hoc comparisons, Scheffe's test, Mann-Whitney $U$ test and $\chi^{2}$ test were used for normally distributed, not normally distributed and categorical variables, respectively. Full model binary logistic regression analyses (including all variables of interest) were applied to assess the independent association of several continuous and categorical variables with each CKD phenotype. Results of these analyses were expressed as OR with $95 \%$ CI. A $p$ value $\leq 0.05$ was considered to be statistically significant (see ESM Methods).

\section{Results}

The main demographic and clinical characteristics of the study cohort are shown in Table 1 along with current pharmacological treatment.

Clinical characteristics by UAE category Normo-, micro- and macroalbuminuria were found in $712(91.6 \%)$, $50(6.4 \%)$ and $15(1.9 \%)$ participants, respectively. Albuminuric individuals were older and had longer diabetes duration, higher $\mathrm{HbA}_{1 \mathrm{c}}, \mathrm{BMI}$, systolic and diastolic $\mathrm{BP}$, LDL-cholesterol and triacylglycerol, and lower eGFR (ESM Table 1). They also had higher $\gamma$-glutamyltransferase (GGT), fibrinogen and uric acid levels. There were more current smokers in the micro-, and fewer in the macro-, compared with the normoalbuminuric groups. Albuminuric individuals were more frequently hypertensive, on BP-lowering agents (and renin-angiotensin system [RAS] blockers) and antiplatelet agents, and had higher daily insulin requirements. Rates of advanced retinopathy, polyneuropathy and CVD increased across the albuminuria categories.

Compared with participants with normal albuminuria $(n=600,77.2 \%)$, those with mildly increased albuminuria ( $n=112,14.4 \%$ ) had higher $\mathrm{HbA}_{1 \mathrm{c}}$ and fibrinogen, higher rates of hypertension and advanced retinopathy, and marginally increased rates of CVD. Use of BP-lowering agents and RAS blockers was more common in the group with mildly increased albuminuria (ESM Table 2).

Clinical characteristics by eGFR category eGFR categories 1,2 and 3 included 445 (57.3\%), 303 (39.0\%) and 29 (3.7\%) participants, respectively. Age, diabetes duration and BMI increased progressively across these categories. $\mathrm{HbA}_{1 \mathrm{c}}$, systolic and diastolic BP, triacylglycerol, GGT, fibrinogen, 
Table 1 Clinical characteristics of the type 1 diabetes cohort as a whole and after stratification by CKD stage

\begin{tabular}{|c|c|c|c|c|c|}
\hline & All patients $(n=777)$ & No CKD $(n=695)$ & Stage $1-2$ CKD $(n=53)$ & Stage $\geq 3$ CKD $(n=29)$ & $p$ value \\
\hline Men/women, n (\%) & $408 / 369(52.5 / 47.5)$ & $359 / 336(51.7 / 48.3)$ & $31 / 22(58.5 / 41.5)$ & $18 / 11(62.1 / 37.9)$ & 0.369 \\
\hline Age, years & $40.2 \pm 11.7$ & $39.4 \pm 11.1$ & $41.8 \pm 12.3$ & $56.2 \pm 13.1 * * * \dagger \dagger$ & $<0.0001$ \\
\hline Age at diabetes diagnosis, years & $20.8 \pm 10.9$ & $20.9 \pm 10.8$ & $18.1 \pm 10.3$ & $24.6 \pm 12.8^{\dagger}$ & 0.031 \\
\hline Duration of diabetes, years & $19.4 \pm 12.2$ & $18.5 \pm 12.0$ & $23.7 \pm 11.3 * *$ & $31.7 \pm 12.1 * * * \dagger$ & $<0.0001$ \\
\hline BMI, $\mathrm{kg} / \mathrm{m}^{2}$ & $24.8 \pm 3.6$ & $24.6 \pm 3.4$ & $26.2 \pm 4.8^{* *}$ & $26.2 \pm 3.7 *$ & $<0.001$ \\
\hline Waist circumference, $\mathrm{cm}$ & $90.8 \pm 10.7$ & $90.3 \pm 10.3$ & $95.7 \pm 13.4 * *$ & $94.1 \pm 12.5$ & $<0.0001$ \\
\hline $\begin{array}{l}\text { Smoking habit (non-smoker/ } \\
\quad \text { current smoker) }(n=762), \mathrm{n}(\%)\end{array}$ & $536 / 226(70.4 / 29.6)$ & $482 / 200(70.7 / 29.3)$ & $32 / 19(62.7 / 37.3)$ & $22 / 7(75.9 / 24.1)$ & 0.497 \\
\hline Fasting glucose, $\mathrm{mmol} / \mathrm{l}$ & $9.44 \pm 4.56$ & $9.22 \pm 4.45$ & $11.22 \pm 4.79 * *$ & $11.58 \pm 5.52 *$ & $<0.0001$ \\
\hline $\mathrm{HbA}_{1 \mathrm{c}}, \%(\mathrm{mmol} / \mathrm{mol})$ & $\begin{array}{l}7.83 \pm 1.17 \\
\quad(62.0 \pm 12.9)\end{array}$ & $\begin{array}{l}7.76 \pm 1.15 \\
\quad(61.4 \pm 12.6)\end{array}$ & $\begin{array}{l}8.46 \pm 1.23 * * * \\
\quad(69.0 \pm 13.4)\end{array}$ & $\begin{array}{l}8.17 \pm 1.26 \\
\quad(65.7 \pm 13.8)\end{array}$ & $<0.0001$ \\
\hline Systolic BP, mmHg & $127 \pm 18$ & $125 \pm 17$ & $134 \pm 19 * * *$ & $152 \pm 18 * * * \dagger$ & $<0.0001$ \\
\hline Diastolic BP, mmHg & $73 \pm 9$ & $73 \pm 8$ & $76 \pm 12^{*}$ & $79 \pm 8 * *$ & $<0.0001$ \\
\hline Total cholesterol, mmol/1 & $4.85 \pm 0.88$ & $4.81 \pm 0.85$ & $5.27 \pm 1.14 * * *$ & $4.88 \pm 1.01$ & $<0.001$ \\
\hline LDL-cholesterol, mmol/l & $3.01 \pm 0.76$ & $2.99 \pm 0.74$ & $3.30 \pm 0.95 *$ & $3.04 \pm 0.82$ & 0.014 \\
\hline \multicolumn{6}{|l|}{ HDL-cholesterol, mmol/1 } \\
\hline Men & $1.45(1.24-1.71)$ & $1.45(1.24-1.68)$ & $1.61(1.35-1.86)$ & $1.37(0.99-1.58)^{\dagger}$ & 0.036 \\
\hline Women & $1.74(1.48-2.07)$ & $1.73(1.48-2.07)$ & $1.75(1.39-2.15)$ & $1.79(1.50-1.97)$ & 0.981 \\
\hline \multicolumn{6}{|l|}{ Triacylglycerol, mmol/1 } \\
\hline Men & $0.90(0.71-1.24)$ & $0.89(0.70-1.19)$ & $1.00(0.82-1.58)$ & $1.25(0.86-2.01)$ & 0.044 \\
\hline Women & $0.78(0.60-1.06)$ & $0.77(0.59-1.04)$ & $0.98(0.75-1.15)^{* *}$ & $1.21(0.70-1.32)$ & 0.005 \\
\hline ALT, U/1 & $20 \pm 11$ & $20 \pm 10$ & $23 \pm 16$ & $21 \pm 6$ & 0.095 \\
\hline AST, U/1 & $22 \pm 32$ & $22 \pm 33$ & $25 \pm 27$ & $22 \pm 13$ & 0.812 \\
\hline GGT, U/1 & $21 \pm 33$ & $19 \pm 25$ & $32 \pm 85^{*}$ & $36 \pm 33^{*}$ & $<0.001$ \\
\hline Uric acid, $\mu \mathrm{mol} / 1$ & $223.8 \pm 67.5$ & $217.4 \pm 58.2$ & $241.4 \pm 72.3^{*}$ & $343.3 \pm 126.9^{* * * * \dagger \dagger}$ & $<0.0001$ \\
\hline Fibrinogen, $\mu \mathrm{mol} / 1$ & $9.89 \pm 2.00$ & $9.75 \pm 1.91$ & $10.93 \pm 2.33^{* * *}$ & $11.41 \pm 2.15^{* * *}$ & $<0.0001$ \\
\hline Creatinine, $\mu \mathrm{mol} / 1$ & $73.4 \pm 18.6$ & $71.2 \pm 12.7$ & $72.2 \pm 13.5$ & $127.1 \pm 46.2 * * *+\dagger$ & $<0.0001$ \\
\hline $\mathrm{ACR}, \mathrm{mg} / \mathrm{mmol}$ & $0.49(0.26-1.02)$ & $0.44(0.24-0.81)$ & $8.11(5.21-22.74)^{* * *}$ & $1.96(0.58-40.38)^{* * *} \dagger$ & $<0.0001$ \\
\hline $\mathrm{eGFR}^{\mathrm{a}}, \mathrm{ml} \mathrm{min}^{-1}[1.73 \mathrm{~m}]^{-2}$ & $95.1 \pm 21.4$ & $97.0 \pm 19.8$ & $95.7 \pm 18.3$ & $49.3 \pm 9.5 * * * \dagger \dagger$ & $<0.0001$ \\
\hline $\begin{array}{l}\text { Daily insulin dose, } \mathrm{U} / \mathrm{kg} \\
\text { body weight }\end{array}$ & $0.66 \pm 0.20$ & $0.66 \pm 0.20$ & $0.71 \pm 0.15$ & $0.71 \pm 0.28$ & 0.103 \\
\hline MDI/CSII, n (\%) & $694 / 83(89.3 / 10.7)$ & $617 / 78(88.8 / 11.2)$ & $48 / 5(90.6 / 9.4)$ & $29 / 0(100 / 0)$ & 0.151 \\
\hline \multicolumn{6}{|l|}{ Treatment, n (\%) } \\
\hline BP-lowering agents & $151(19.4)$ & $99(14.3)$ & $31(58.5)^{* * *}$ & $21(72.4)^{* * *}$ & $<0.0001$ \\
\hline RAS blockers & $136(17.5)$ & $87(12.5)$ & $30(56.6) * * *$ & $19(65.5)^{* * *}$ & $<0.0001$ \\
\hline Lipid-lowering agents & $100(12.9)$ & 79 (11.4) & $8(15.1)$ & $13(44.8)^{* * * * \dagger}$ & $<0.0001$ \\
\hline Antiplatelet agents & $50(6.4)$ & $33(4.8)$ & $7(13.2)^{*}$ & $10(34.5)^{* * *}{ }^{\dagger}$ & $<0.0001$ \\
\hline Metformin & $46(5.9)$ & $41(5.9)$ & $1(1.9)$ & $4(13.8)$ & 0.092 \\
\hline Hypertension, n (\%) & $273(35.1)$ & $207(29.9)$ & $39(73.6)^{* * *}$ & $27(93.1)^{* * *}{ }^{\dagger}$ & $<0.0001$ \\
\hline $\begin{array}{l}\text { Retinopathy: no/non-advanced/ } \\
\text { advanced }(n=753), \mathrm{n}(\%)\end{array}$ & $\begin{array}{l}441 / 194 / 118 \\
(58.5 / 25.8 / 15.7)\end{array}$ & $\begin{array}{l}423 / 175 / 77 \\
(62.7 / 25.9 / 11.4)\end{array}$ & $\begin{array}{l}15 / 12 / 24 * * * \\
(29.4 / 23.5 / 47.1)\end{array}$ & $\begin{array}{l}3 / 7 / 17 * * * \\
\quad(11.1 / 25.9 / 63.0)\end{array}$ & $<0.0001$ \\
\hline $\begin{array}{l}\text { Peripheral polyneuropathy: } \\
\text { no/yes }(n=731), \mathrm{n}(\%)\end{array}$ & $\begin{array}{l}671 / 60 \\
\quad(91.8 / 8.2)\end{array}$ & $\begin{array}{l}619 / 39 \\
\quad(94.1 / 5.9)\end{array}$ & $\begin{array}{l}39 / 9 * * \\
\quad(81.2 / 18.8)\end{array}$ & $\begin{array}{l}13 / 12 * * * \dagger \\
(52.0 / 48.0)\end{array}$ & $<0.0001$ \\
\hline Cardiovascular events, n (\%) & $66(8.5)$ & $50(7.2)$ & $6(11.3)$ & $10(34.5)^{* * * \dagger}$ & $<0.0001$ \\
\hline Autoimmune thyropathy, n (\%) & $113(14.5)$ & $103(14.8)$ & $7(13.2)$ & $3(10.3)$ & 0.765 \\
\hline
\end{tabular}

Quantitative variables are shown as mean $\pm \mathrm{SD}$ or median (IQR)

${ }^{\mathrm{a}}$ Based on the MDRD equation

$* p<0.05 ; * *<<0.01 ; * * * p<0.001$ vs no CKD

${ }^{\dagger} p<0.05 ;{ }^{\dagger \dagger} p<0.01 ;{ }^{\dagger \dagger \dagger} p<0.001$ vs stage $1-2 \mathrm{CKD}$

ALT, alanine aminotransferase; AST, aspartate aminotransferase; MDI/CSII, multiple daily insulin injections/continuous subcutaneous insulin infusion 
uric acid, ACR, rates of treatment with BP-lowering (and RAS blockers), lipid-lowering and antiplatelet agents, and prevalence of hypertension, advanced retinopathy, polyneuropathy and CVD were all higher, and HDL-cholesterol lower in eGFR category 3 compared with categories 1 and 2. Categories 1 and 2 showed similar levels for all variables (ESM Table 3). Compared with individuals with eGFR 75-89 $(n=232,29.9 \%)$, those with eGFR 60-74 $\mathrm{ml} \mathrm{min}^{-1}[1.73 \mathrm{~m}]^{-2}(n=71,9.1 \%)$ had longer diabetes duration, higher rates of treatment with BP-lowering agents and higher prevalence of hypertension and advanced diabetic retinopathy (ESM Table 4).

Clinical characteristics by CKD stage Based on eGFR and ACR, 695 individuals (89.4\%) had no CKD, with stages 1-2 and $\geq 3$ CKD including $6.8 \%(n=53)$ and $3.7 \%(n=29)$ of the participants, respectively. Microalbuminuria was more prevalent in individuals with stage 1-2 CKD (46/53, $86.8 \%$ ), while macroalbuminuria was more common in those with stage $\geq 3 \operatorname{CKD}(8 / 29,27.6 \% ; p=0.0004$; Fig. 1). Sex distribution, smoking habits, and daily insulin dose were comparable across the CKD stages. Those with stage $\geq 3$ CKD were older, had higher uric acid and, by definition, higher creatinine and lower eGFR. These variables did not differ between stage 1-2 CKD and no CKD (Table 1). BMI, waist, $\mathrm{HbA}_{1 \mathrm{c}}$, diastolic $\mathrm{BP}$, GGT, fibrinogen, treatment with BP-lowering agents and RAS blockers, and prevalence of hypertension were higher in those with stages $1-2$ and $\geq 3$ CKD compared with no CKD. Finally, diabetes duration, systolic BP, use of lipid-lowering and antiplatelet agents, and prevalence of advanced retinopathy (Fig. 1), polyneuropathy and CVD progressively increased with CKD stage (Table 1). Lipid-lowering treatment most probably accounts for the higher LDL-cholesterol level observed in those with stage $1-2$, but not in stage $\geq 3 \mathrm{CKD}$, compared with no CKD.

Albuminuric and non-albuminuric phenotypes in individuals with stage $\geq \mathbf{3}$ CKD Of 29 participants with stage $\geq 3$ CKD, albuminuria $\left(\geq 3.4 \mathrm{mg} / \mathrm{mmol} ; \mathrm{Alb}^{+}\right)$was detected in 12 $(41.4 \%)$, with the remaining $17(58.6 \%)$ having a non-albuminuric $\left(\mathrm{Alb}^{-}\right)$phenotype (Table 2$)$. There were no significant differences between the phenotypes for most of the variables considered including age, diabetes duration and sex, with the exception of lower eGFR $(45.2 \pm 10.8$ vs $\left.52.2 \pm 7.4 \mathrm{ml} \mathrm{min}^{-1}[1.73 \mathrm{~m}]^{-2}, p=0.048\right)$ and marginally higher $\mathrm{HbA}_{1 \mathrm{c}}(8.62 \pm 1.33$ vs $7.84 \pm 1.13 \%[70.8 \pm 14.6$ vs $62.2 \pm 12.4 \mathrm{mmol} / \mathrm{mol}] ; p=0.080)$ in the $\mathrm{Alb}^{+}$group (ESM Table 5). Interestingly, there were no differences between the phenotypes for the distribution of retinopathy (Fig. 1), rate of hypertension or CVD, or the use of BP-lowering agents or RAS blockers.

$\mathrm{Alb}^{+}$and $\mathrm{Alb}^{-}$phenotypes in individuals with eGFR $<75 \mathrm{ml} \mathrm{min}^{-1}[1.73 \mathrm{~m}]^{-2}$ Of the 71 individuals with eGFR $60-74 \mathrm{ml} \mathrm{min}^{-1}[1.73 \mathrm{~m}]^{-2}$, eight $(11.3 \%)$ and $63(88.7 \%)$ had $\mathrm{Alb}^{+}$and $\mathrm{Alb}^{-}$phenotypes, respectively (Table 3 ). Within this sub-category, albuminuria was normal (ACR $<1.1 \mathrm{mg} / \mathrm{mmol}$ ) in most of the participants $(50 / 71,70.4 \%)$. The percentage of individuals with normal albuminuria was lower, although still relevant, in patients in stage $\geq 3 \mathrm{CKD}(10 / 29,34.5 \%$; Table 2$)$.
Fig. 1 CKD stage and phenotype distribution in the study cohort. Microalbuminuria was more prevalent among individuals with stage 1-2 CKD (86.8\%) and macroalbuminuria among individuals with stage $\geq 3 \mathrm{CKD}$ $(66.7 \% ; p=0.0004)$. Prevalence of advanced retinopathy increased with increasing CKD stage (no CKD $<$ stage $1-2 \mathrm{CKD}<$ stage $\geq 3$ CKD; $p<0.0001$ ) with no differences between nonalbuminuric and albuminuric stage $\geq 3$ CKD. Data on retinopathy were available for 753 individuals. Data are expressed as $n(\%)$

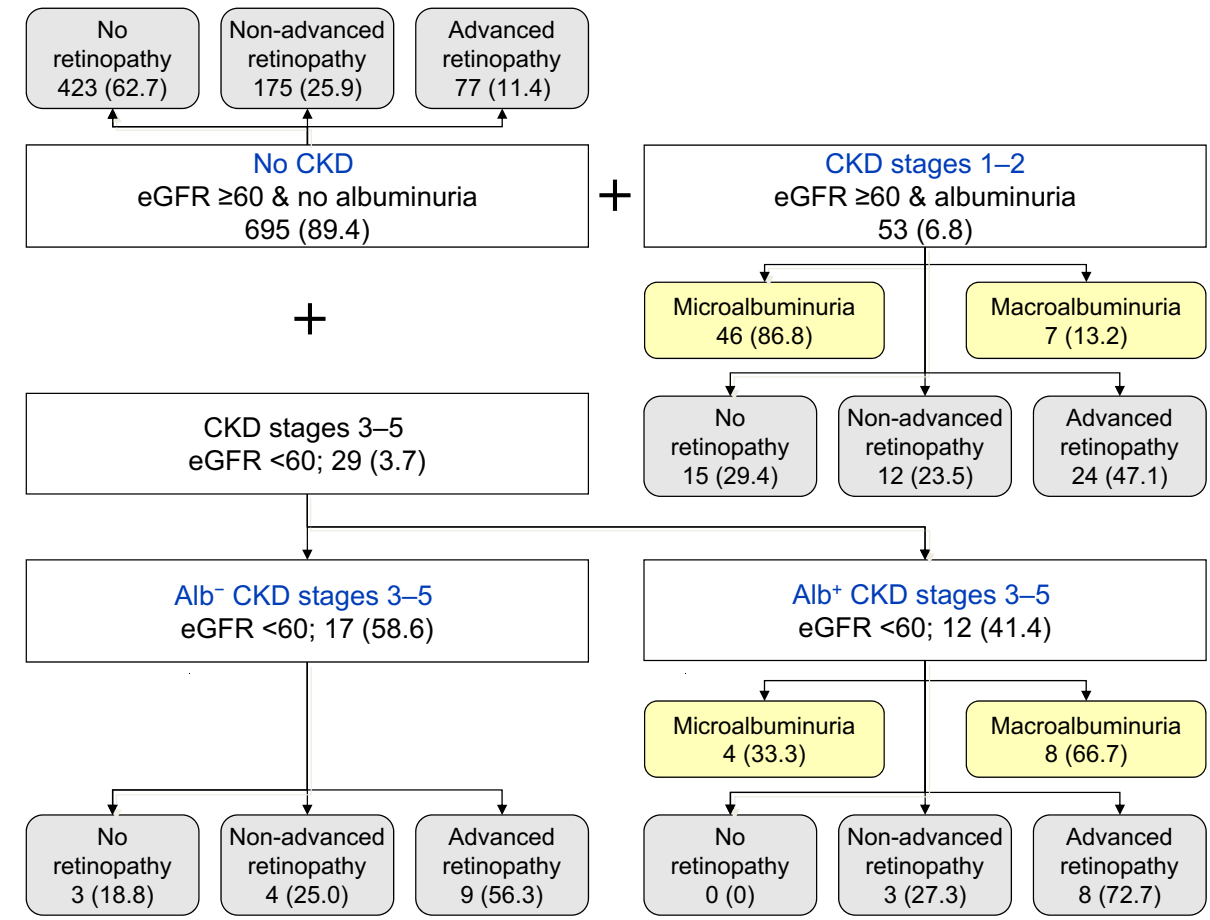


Table 2 Distribution of albuminuric and non-albuminuric phenotypes by eGFR category. $\mathrm{Alb}^{-}$and $\mathrm{Alb}^{+} \mathrm{CKD}$ phenotypes are defined as for the binary logistic regression analysis described in Tables 4 and 5

\begin{tabular}{|c|c|c|c|c|c|}
\hline & \multicolumn{4}{|c|}{ 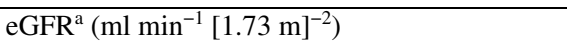 } & \multirow{2}{*}{ Total } \\
\hline & $\geq 90$ & $75-89$ & $60-74$ & $<60$ & \\
\hline$n$ & 445 & 232 & 71 & 29 & 777 \\
\hline $\begin{array}{l}\text { Normal albuminuria } \\
(<1.1 \mathrm{mg} / \mathrm{mmol})\end{array}$ & $353(79.4)$ & $187(80.6)$ & $50(70.4)$ & $10(34.5)$ & $600(77.2)$ \\
\hline $\begin{array}{l}\text { Mildly increased albuminuria } \\
(1.1-3.4 \mathrm{mg} / \mathrm{mmol})\end{array}$ & $61(13.7)$ & $31(13.4)$ & $13(18.3)$ & $7(24.1)$ & $112(14.4)$ \\
\hline $\begin{array}{l}\text { Moderately increased } \\
\text { albuminuria (3.4-34 } \\
\mathrm{mg} / \mathrm{mmol})\end{array}$ & $25(5.6)$ & $14(6.0)$ & $7(9.9)$ & $4(13.8)$ & $50(6.4)$ \\
\hline $\begin{array}{l}\text { Severely increased } \\
\text { albuminuria ( } \geq 34 \mathrm{mg} / \mathrm{mmol})\end{array}$ & $6(1.3)$ & - & $1(1.4)$ & $8(27.6)$ & $15(1.9)$ \\
\hline
\end{tabular}

Data are expressed as number and percentage

Green, no CKD ( $n=695)$; yellow, stages $1-2 \mathrm{CKD}(n=53)$; orange, non-albuminuric stages $\geq 3 \mathrm{CKD}(n=17)$; red, albuminuric stages $\geq 3 \mathrm{CKD}(n=12)$

${ }^{a}$ Based on the MDRD equation

The 21 individuals in the eGFR $60-74 \mathrm{ml} \mathrm{min}^{-1}[1.73 \mathrm{~m}]^{-2}$ sub-category with mildly-to-severely increased albuminuria were older, had longer diabetes duration, were heavier and had larger waist circumference, and higher $\mathrm{HbA}_{1 \mathrm{c}}$ $(8.50 \pm 1.28$ vs $7.60 \pm 0.91 \%[69.4 \pm 13.9 \mathrm{vs}$ $59.6 \pm 10.1 \mathrm{mmol} / \mathrm{mol}] ; p=0.016)$ and fibrinogen levels compared with the 50 individuals with normal albuminuria.

When stage $\geq 3$ CKD and the eGFR $60-74 \mathrm{ml} \mathrm{min}^{-1}$ $[1.73 \mathrm{~m}]^{-2}$ sub-category were pooled $(n=100$; ESM Table 6), the $\mathrm{Alb}^{+}$group $(n=40)$ had higher BMI, larger waist circumference, higher $\mathrm{HbA}_{1 \mathrm{c}}$, fibrinogen, triacylglycerol, systolic BP and lower HDL-cholesterol (all $p<0.05$ ) than the $\mathrm{Alb}^{-}$group $(n=60)$. There were no differences in age, diabetes duration, smoking habits and rate of CVD. The $\mathrm{Alb}^{+}$group included more men ( 57.5 vs $33.9 \%, p=0.024)$, had greater prevalence of hypertension ( 81.1 vs $44.8 \%, p=0.001$ ), and BP-lowering agents $(60.0$ vs $28.5 \%, p=0.003)$ or RAS blockers (55.0 vs $23.7 \%, p=0.003)$ and had higher rates of advanced retinopathy $(62.5$ vs $27.6 \%, p=0.003)$.

Factors associated with different CKD phenotypes The independent association of continuous and categorical

Table 3 Distribution of albuminuric and non-albuminuric phenotypes by eGFR category. CKD phenotypes are defined as for the binary logistic regression analysis described in Table 5

\begin{tabular}{|c|c|c|c|c|c|}
\hline & \multicolumn{4}{|c|}{ 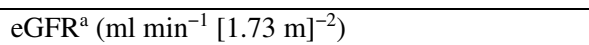 } & \multirow{2}{*}{ Total } \\
\hline & $\geq 90$ & $75-89$ & $60-74$ & $<60$ & \\
\hline$n$ & 445 & 232 & 71 & 29 & 777 \\
\hline $\begin{array}{l}\text { Normal albuminuria } \\
(<1.1 \mathrm{mg} / \mathrm{mmol})\end{array}$ & $353(79.4)$ & $187(80.6)$ & $50(70.4)$ & $10(34.5)$ & $600(77.2)$ \\
\hline $\begin{array}{l}\text { Mildly increased } \\
\text { albuminuria (1.1-3.4 } \\
\mathrm{mg} / \mathrm{mmol})\end{array}$ & $61(13.7)$ & $31(13.4)$ & $13(18.3)$ & $7(24.1)$ & $112(14.4)$ \\
\hline $\begin{array}{l}\text { Moderately increased } \\
\text { albuminuria (3.4-34 } \\
\mathrm{mg} / \mathrm{mmol})\end{array}$ & $25(5.6)$ & $14(6.0)$ & $7(9.9)$ & $4(13.8)$ & $50(6.4)$ \\
\hline $\begin{array}{l}\text { Severely increased } \\
\text { albuminuria ( } \geq 34 \mathrm{mg} / \mathrm{mmol})\end{array}$ & $6(1.3)$ & - & $1(1.4)$ & $8(27.6)$ & $15(1.9)$ \\
\hline
\end{tabular}

Data are expressed as number and percentage

Green, no CKD ( $n=540)$; yellow, mildly-to-severely increased albuminuria and eGFR $\geq 75 \mathrm{ml} \mathrm{min}^{-1}[1.73 \mathrm{~m}]^{-2}(n=137)$; orange, normal albuminuria and eGFR $<75 \mathrm{ml} \mathrm{min}^{-1}[1.73 \mathrm{~m}]^{-2}(n=60)$; red, mildly-to-severely increased albuminuria and eGFR $<75 \mathrm{ml} \mathrm{min}^{-1}[1.73 \mathrm{~m}]^{-2}(n=40)$

${ }^{\mathrm{a}}$ Based on the MDRD equation 
variables with the CKD phenotypes was assessed using binary logistic regression analysis (Tables 4,5 ).

Stages $1-2$ and $\geq 3$ CKD were associated with systolic BP and/or hypertension, $\mathrm{HbA}_{1 \mathrm{c}}$, GGT and fibrinogen. Age was directly related to stage $\geq 3 \mathrm{CKD}$ and inversely related to stage 1-2 CKD. Diabetes duration and total cholesterol were only related to stage 1-2 CKD (model 1). The inclusion of retinopathy (model 2) removed diabetes duration and $\mathrm{HbA}_{1 \mathrm{c}}$ as independent covariates of stages $1-2$ and $\geq 3 \mathrm{CKD}$, respectively (Table 4).

Notably, stage $\geq 3 \mathrm{CKD} \mathrm{Alb}^{+}$was independently associated with diabetes duration and $\mathrm{HbA}_{1 \mathrm{c}}$, systolic $\mathrm{BP}$, fibrinogen and, in an inverse manner, HDL-cholesterol. In contrast, $\mathrm{CKD} \mathrm{Alb}{ }^{-}$was related to age, hypertension, systolic $\mathrm{BP}$ and GGT, but not to diabetes duration and $\mathrm{HbA}_{1 \mathrm{c}}$. There was no association with use of antihypertensive agents (model 1). Inclusion of retinopathy (model 2) removed diabetes duration as a covariate for stage $\geq 3 \mathrm{CKD} \mathrm{Alb}^{+}$, with no effect on the covariates for stage $\geq 3 \mathrm{CKD} \mathrm{Alb}^{-}$ (Table 5).
Overall, the sensitivity analysis performed in individuals with eGFR $<75 \mathrm{ml} \mathrm{min}^{-1}[1.73 \mathrm{~m}]^{-2}$ confirmed the results (Table 5).

\section{Discussion}

Our results support the emerging view that in type 1 diabetes $\mathrm{CKD}$ is more heterogeneous than commonly believed. Even though the $\mathrm{Alb}^{+}$phenotype remains predominant (79.3\%), in our cohort more than half of the participants with stage $\geq 3$ CKD (58.6\%) displayed the $\mathrm{Alb}^{-}$phenotype. It may also be worth pointing out that the overall prevalence of the $\mathrm{Alb}^{-}$ CKD phenotype (2\%) is much lower than it has been reported in type 2 diabetes $(10 \%)$ [11]; this probably reflects a greater prevalence of hypertension, CVD and obesity in the latter group [11]. These findings are of relevance since most studies investigating the prevalence of non-albuminuric CKD have been performed in type 2 diabetes, where as many as $36 \%$ [8] to $62 \%$ [10] of individuals with renal insufficiency do

Table 4 Independent correlates of stage 1-2 CKD and stage $\geq 3$ CKD vs no CKD (the reference group)

\begin{tabular}{|c|c|c|c|c|c|c|}
\hline & \multicolumn{3}{|c|}{ Stage $1-2$ CKD $(n=53)$} & \multicolumn{3}{|c|}{ Stage $\geq 3$ CKD $(n=29)$} \\
\hline & OR & $95 \% \mathrm{CI}$ & $p$ value & OR & $95 \% \mathrm{CI}$ & $p$ value \\
\hline \multicolumn{7}{|l|}{ Model $1^{\mathrm{a}}$} \\
\hline Age, 1 year & 0.950 & $0.912,0.989$ & 0.012 & 1.070 & $1.025,1.117$ & 0.002 \\
\hline Duration of diabetes, 1 year & 1.048 & $1.012,1.084$ & 0.008 & 1.046 & $0.996,1.099$ & 0.072 \\
\hline $\mathrm{HbA}_{1 \mathrm{c}}, 1 \mathrm{mmol} / \mathrm{mol}$ & 1.041 & $1.015,1.067$ & 0.002 & 1.044 & $1.005,1.086$ & 0.028 \\
\hline Total cholesterol, $1 \mathrm{mmol} / \mathrm{l}$ & 1.406 & $1.007,1.962$ & 0.045 & 1.242 & $0.661,2.334$ & 0.501 \\
\hline GGT, $1 \mathrm{U} / 1$ & 1.006 & $1.000,1.012$ & 0.035 & 1.017 & $1.006,1.028$ & 0.003 \\
\hline Fibrinogen, $1 \mu \mathrm{mol} / 1$ & 1.220 & $1.025,1.451$ & 0.025 & 1.440 & $1.110,1.867$ & 0.006 \\
\hline Hypertension & 5.582 & $2.335,13.341$ & 0.0001 & 9.756 & $1.473,64.629$ & 0.018 \\
\hline Systolic BP, $1 \mathrm{mmHg}$ & 0.999 & $0.974,1.025$ & 0.956 & 1.027 & $1.001,1.053$ & 0.045 \\
\hline \multicolumn{7}{|l|}{ Model $2^{\mathrm{b}}$} \\
\hline Age, 1 year & 0.944 & $0.903,0.986$ & 0.009 & 1.071 & $1.008,1.137$ & 0.025 \\
\hline Duration of diabetes, 1 year & 1.005 & $0.963,1.050$ & 0.810 & 1.010 & $0.951,1.072$ & 0.758 \\
\hline $\mathrm{HbA}_{1 \mathrm{c}}, 1 \mathrm{mmol} / \mathrm{mol}$ & 1.036 & $1.009,1.063$ & 0.009 & 1.025 & $0.979,1.073$ & 0.293 \\
\hline Total cholesterol, $1 \mathrm{mmol} / \mathrm{l}$ & 1.487 & $1.050,2.106$ & 0.025 & 1.334 & $0.669,2.662$ & 0.413 \\
\hline GGT, $1 \mathrm{U} / 1$ & 1.006 & $1.000,1.012$ & 0.035 & 1.019 & $1.007,1.031$ & 0.003 \\
\hline Fibrinogen, $1 \mu \mathrm{mol} / 1$ & 1.204 & $0.999,1.451$ & 0.051 & 1.468 & $1.104,1.951$ & 0.008 \\
\hline Hypertension & 5.102 & $2.037,12.776$ & 0.001 & 6.697 & $1.058,42.399$ & 0.043 \\
\hline Systolic BP, $1 \mathrm{mmHg}$ & 0.998 & $0.970,1.027$ & 0.895 & 1.025 & $0.998,1.053$ & 0.066 \\
\hline Retinopathy & & & 0.0001 & & & 0.003 \\
\hline No & 1 & & & 1 & & \\
\hline Non-advanced & 1.470 & $0.584,3.698$ & 0.413 & 1.747 & $0.547,13.857$ & 0.220 \\
\hline Advanced & 10.242 & $4.216,24.879$ & 0.0001 & 9.877 & $2.200,44.350$ & 0.003 \\
\hline
\end{tabular}

${ }^{\text {a }}$ Other variables included in model 1 but never selected as significant independent covariates: sex, BMI, smoking, diastolic BP, HDL-cholesterol, triacylglycerol, uric acid, RAS blockers

${ }^{\mathrm{b}}$ Other variables included in model 2 but never selected as significant independent covariates: sex, BMI, smoking, diastolic BP, HDL-cholesterol, triacylglycerol, uric acid, RAS blockers 





not present with albuminuria. On the contrary, the prevalence of different CKD phenotypes (i.e. with and without albuminuria) and clinical and biochemical factors associated with increasing albuminuria vs decreasing GFR as separate entities have been poorly described in type 1 diabetes.

The appreciation of normoalbuminuric CKD is at variance with some of the classic studies. For example, The Pittsburgh Epidemiology of Diabetes Complications Study showed that eGFR reduction $<60 \mathrm{ml} \mathrm{min}^{-1}[1.73 \mathrm{~m}]^{-2}$ occurred rarely in type 1 diabetes patients with no prior/concurrent albuminuria [29]. A different picture was described by the DCCT/EDIC where a sizeable percentage (24\%) of individuals developing persistent eGFR reduction $<60 \mathrm{ml} \mathrm{min}^{-1}[1.73 \mathrm{~m}]^{-2}$ had an AER $<30 \mathrm{mg} /$ $24 \mathrm{~h}$ in the preceding 19 years [15]. Similarly, a cross-sectional survey of the UK National Diabetes Audit reported that albuminuria was absent in $54.4 \%$ of individuals with type 1 diabetes and stage $\geq 3 \mathrm{CKD}$ [30]. In our cohort the overall prevalence of normoalbuminuric CKD was $2.2 \%$, similar to that reported in the larger population of the FinnDiane Study ( $n=3809,2.0 \%$ ) [31]. The two studies, however, differ in that in the FinnDiane Study non-albuminuric CKD accounted for $6.1 \%$ of all patients with any CKD phenotype and $15.5 \%$ of all individuals with stage $\geq 3 \mathrm{CKD}$, while these figures are $20.7 \%$ and $58.6 \%$, respectively, in our cohort. These differences are not easy to reconcile but our population is representative of a specific geographical area and reflects clinical management in a single centre as opposed to a population collected at national level and from different centres, which could have introduced more variability. Our results remained substantially unaffected by including individuals with eGFR $60-74 \mathrm{ml} \mathrm{min}^{-1}[1.73 \mathrm{~m}]^{-2}$ and those with mildly increased albuminuria (i.e. those with an ACR of 1.1$3.4 \mathrm{mg} / \mathrm{mmol}$ ). Even with this broader categorisation, the $\mathrm{Alb}^{-}$ phenotype (eGFR $<75 \mathrm{ml} \mathrm{min}^{-1}[1.73 \mathrm{~m}]^{-2}$ ) accounted for a similar proportion (60\%) of all participants. In summary, at least $50 \%$ of individuals with type 1 diabetes with an eGFR $<60 \mathrm{ml} \mathrm{min}{ }^{-1}[1.73 \mathrm{~m}]^{-2}$ are normoalbuminuric, and some may well progress to a more advanced stage of renal failure without manifesting albuminuria as indicated by normal UAE in $34.5 \%$ of individuals with stage $\geq 3 \mathrm{CKD}$.

Despite the cross-sectional nature of our study, we speculate that, in a sizeable proportion of the type 1 diabetes population, the decline in GFR can progress without albuminuria or even anticipate its appearance. These results are in line with those of Zerbini et al. [32] who demonstrated, over a 9.5 year follow-up in 146 young individuals with type 1 diabetes, a faster decline in GFR prior to the appearance of microalbuminuria. These observations have prompted the identification of a novel phenotype, the early renal function decline (ERFD), in the development of CKD in type 1 diabetes $[33,34]$. Both the First and the Second Joslin Study of Natural History of Microalbuminuria in Type 1 Diabetes reported ERFD (defined as loss in GFR that exceeds $3.3 \%$ per year) to evolve in up to $9-10 \%$ of normoalbuminuric individuals with type 1 diabetes $[33,35]$. Moreover, in the series by Perkins et al. [36] about half of the individuals progressing to advanced CKD experienced only persistent microalbuminuria with some even reverting to normoalbuminuria [36]. These observations are in agreement with our data showing a high proportion of individuals (70.4\%) with normal albuminuria (ACR $<1.1 \mathrm{mg} / \mathrm{mmol}$ ) who already had a reduction, although mild, in eGFR $\left(60-74 \mathrm{ml} \mathrm{min}^{-1}[1.73 \mathrm{~m}]^{-2}\right)$. The two phenotypes may also differentiate in terms of outcomes, as ERFD appears to be more frequent in $\mathrm{Alb}^{+}$than in $\mathrm{Alb}^{-}$patients [33, 35], and the rate of GFR loss tends to be faster in patients with micro- than in those with normoalbuminuria [36, 37].

In summary, our observations and the available evidence support the hypothesis that UAE and loss of GFR may not necessarily represent stages of a common pathway; rather they may be independent markers of progression of the disease [38]. This is further supported by the identification of distinct sets of risk factors for GFR loss vs progression of UAE.

In our cohort, age was an independent predictor in the $\mathrm{Alb}^{-}$ but not in the $\mathrm{Alb}^{+}$groups even though there was no difference in age between the two groups within stage $\geq 3$ CKD and CKD stages with eGFR $<75 \mathrm{ml} \mathrm{m^{-1 }}[1.73 \mathrm{~m}]^{-2}$. The $\mathrm{Alb}^{-}$ subgroup, however, was younger within the $60-74 \mathrm{ml} \mathrm{min}^{-1}$ $[1.73 \mathrm{~m}]^{-2}$ eGFR sub-category. In line with these results, $\mathrm{Alb}^{-} \mathrm{CKD}$ has been reported in relatively young patients with type 1 diabetes in several studies $[14,15]$. The $\mathrm{Alb}^{-} \mathrm{CKD}$ phenotype within those with eGFR $<75 \mathrm{ml} \mathrm{min}^{-1}[1.73 \mathrm{~m}]^{-2}$ was also independently related to female sex, similar to the findings of the FinnDiane Study [31].

In our survey, the $\mathrm{Alb}^{+} \mathrm{CKD}$ phenotype was strongly associated with diabetes features. With individuals without $\mathrm{CKD}$ as a reference group, $\mathrm{HbA}_{1 \mathrm{c}}$ was independently associated with stages $1-2$ and $\geq 3 \mathrm{CKD}$ and with stage $\geq 3 \mathrm{CKD} \mathrm{Alb}{ }^{+}$, but not with stage $\geq 3 \mathrm{CKD} \mathrm{Alb}^{-}$. Consistently, diabetes dura-

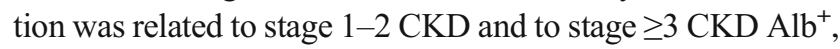
but not with stage $\geq 3 \mathrm{CKD} \mathrm{Alb}^{-}$. Sensitivity analysis confirmed the association of diabetes duration and $\mathrm{HbA}_{1 \mathrm{c}}$ with eGFR $<75 \mathrm{ml} \mathrm{min}{ }^{-1}[1.73 \mathrm{~m}]^{-2} \mathrm{Alb}^{+}$, but not with eGFR $<75 \mathrm{ml} \mathrm{min}{ }^{-1}[1.73 \mathrm{~m}]^{-2} \mathrm{Alb}^{-}$. These findings are in line with reports from the FinnDiane Study [31] and the Second Joslin Study [35]. In the latter, the risk of renal functional decline in normoalbuminuric individuals was independent of $\mathrm{HbA}_{1 \mathrm{c}}$ quartile, but increased from the lowest to the highest quartile in the microalbuminuric group.

When included in the model, retinopathy, a condition strongly associated with chronic hyperglycaemia, entered in the regression by displacing diabetes duration in stage 1-2 $\mathrm{CKD}$, and $\mathrm{HbA}_{1 \mathrm{c}}$ in stage $\geq 3 \mathrm{CKD}$ (Table 4). Furthermore, retinopathy displaced diabetes duration, not $\mathrm{HbA}_{1 \mathrm{c}}$, in stage $\geq 3 \mathrm{CKD} \mathrm{Alb}^{+}$and both diabetes duration and $\mathrm{HbA}_{1 \mathrm{c}}$ in eGFR $<75 \mathrm{ml} \mathrm{min}^{-1}[1.73 \mathrm{~m}]^{-2} \mathrm{Alb}^{+}$, thus performing as an independent covariate for almost all $\mathrm{CKD} \mathrm{Alb}^{+}$ phenotypes. Retinopathy was also independently related to 
stage $\geq 3 \mathrm{CKD} \mathrm{Alb}^{-}$and to eGFR $<75 \mathrm{ml} \mathrm{min}^{-1}[1.73 \mathrm{~m}]^{-2}$ $\mathrm{Alb}^{-}$. History of retinal laser treatment was also associated with both albuminuric and non-albuminuric CKD in the FinnDiane Study [31].

In our study, all CKD phenotypes were associated with hypertension and/or systolic BP, while no association was found with antihypertensive treatment or specific antihypertensive agents, such as RAS blockers. By indication, use of RAS blockers was more common in patients with stages $1-2$ and $\geq 3$ CKD than in individuals with no CKD, with no difference between stage $\geq 3 \mathrm{CKD} \mathrm{Alb}^{+}$and $\mathrm{Alb}^{-}$ phenotypes. In particular, use of RAS blockers was more

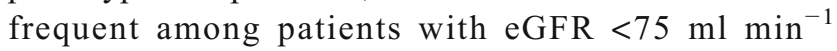
$[1.73 \mathrm{~m}]^{-2} \mathrm{Alb}^{+}$than in those with eGFR $<75 \mathrm{ml} \mathrm{min}^{-1}$ $[1.73 \mathrm{~m}]^{-2} \mathrm{Alb}^{-}$. Overall, these observations suggest that RAS blockage has no effect on non-albuminuric renal insufficiency. In the FinnDiane Study, non-albuminuric CKD was associated with the number of antihypertensive drugs, but not BP levels, antihypertensive treatment or specific renoprotecting antihypertensive agents [31]. In the Second Joslin Study [35], the risk of decline in renal function increased with systolic BP in both individuals with normo- as well as those with microalbuminuria and, at variance to both the FinnDiane Study [31] and our study, also increased with the number of prescribed nephroprotecting treatments. Increased renal vascular resistance in patients with hypertension can be related to systemic haemodynamics and the presence of subclinical atherosclerosis contributing to the decline in GFR in non-albuminuric CKD [39]. Furthermore, in a study of type 1 diabetes, renal vascular resistance, as reflected by raised systemic vascular stiffness and intraglomerular pressure, was lower in healthy nondiabetic individuals than in normoalbuminuric and microalbuminuric individuals with type 1 diabetes [40].

While uric acid has been proposed as a marker for decline in GFR in people with diabetes more than for progression of albuminuria [19, 37, 41], we could not find an independent association with any CKD phenotype. On the contrary plasma fibrinogen levels were independently related to the CKD $\mathrm{Alb}^{+}$ phenotypes (CKD stage 1-2, as well as both stage $\geq 3 \mathrm{Alb}^{+}$ and individuals with eGFR $<75 \mathrm{ml} \mathrm{min}{ }^{-1}[1.73 \mathrm{~m}]^{-2} \mathrm{Alb}^{+}$), but not to $\mathrm{Alb}^{-}$phenotypes. Fibrinogen is a marker of inflammatory vascular changes and endothelial dysfunction $[42,43]$ that, in the DCCT/EDIC, was related to albuminuria [44]. Finally, in our cohort, GGT was an independent covariate of stage 1-2 CKD and of stage $\geq 3 \mathrm{CKD} \mathrm{Alb}^{-}$and $\mathrm{Alb}^{+}$phenotypes, but not in individuals with eGFR $<75 \mathrm{ml} \mathrm{min}{ }^{-1}[1.73 \mathrm{~m}]^{-2}$. GGT, a marker of cell oxidative stress, has been suggested as a predictor for low-grade albuminuria [45]. In a recent population-based study, the prevalence of albuminuria increased from the lowest to the highest GGT quartile, while eGFR correlated inversely across all GGT quartiles [45]. Moreover, it predicts microvascular and/or renal complications in advanced CKD irrespective of $\mathrm{UAE}[46,47]$.

Some limitations of our study must be considered. First, this is a single-centre study limited to individuals of white ethnicity. As in many other studies [31,35] we have no direct measurements of GFR and its estimation was based on a single creatinine measurement. Hence, some individuals may have had temporary reductions in eGFR rather than persistent CKD. This could be especially the case in participants with eGFR $60-74 \mathrm{ml} \mathrm{m^{-1 }}[1.73 \mathrm{~m}]^{-2}$. However, expanding the CKD definition to include this subset of individuals confirmed and strengthened the association with diabetic retinopathy and other covariates, supporting the overall correctness of our phenotype definition. The single assessment of eGFR does not allow us to describe changes over the time, which may be of relevance with respect to spontaneous or drug-mediated remission of microalbuminuria [16-18, 48], although the almost universal use of RAS blockers in type 1 diabetes with increased UAE tends to offset the latter. Furthermore, the cross-sectional nature of the study does not allow exploration of the predictive value of different CKD phenotypes for end-stage renal disease, cardiovascular events and all-cause mortality. Interestingly, in the FinnDiane Study [28], $\mathrm{Alb}^{-} \mathrm{CKD}$ had the same risk of cardiovascular morbidity and all-cause mortality as patients with the $\mathrm{Alb}^{+}$ stage 1-2 CKD, but did not increase the risk of renal outcomes. Finally, our results are based on the MDRD formula for calculation of eGFR. However, the conclusions of our analysis did not change if the CKD-EPI equation was used (data not shown).

In conclusion, we found that non-albuminuric CKD phenotypes are present in a significant proportion of the type 1 diabetes population, in line with previous reports [35]. This challenges the paradigm of renal functional decline following the appearance of albuminuria. Rather, our findings support the hypothesis of two distinct pathways $\left(\mathrm{Alb}^{-}\right.$and $\left.\mathrm{Alb}^{+}\right)$both potentially progressing to advanced kidney disease [38]. This hypothesis is corroborated by the appreciation that distinct covariates relate to the two CKD phenotypes.

Acknowledgements We are indebted to the patients attending the outpatients diabetic clinic and to the staff of the Renzo Navalesi Diabetes Centre in Pisa, particularly to the Clinical Laboratory and the Medical Records Unit.

Data availability The datasets generated and/or analysed during the current study are available from the corresponding author on reasonable request.

Funding This work was supported by a grant from Regione Toscana, Italy, Resolution 1157 (19 December 2011), ID number D55E11002680005. The funding body had no role in study design, data collection and analysis, decision to publish or preparation of the manuscript. 
Duality of interest The authors declare that there is no duality of interest associated with this manuscript.

Author contribution GP, RM and SDP designed the study, drafted the manuscript and approved its final version. ER, MG, GD and DL contributed to the study design, and analysis and interpretation of data, and revised the article's intellectual content and approved the final version. $\mathrm{ER}, \mathrm{MG}, \mathrm{LG}, \mathrm{VSB}, \mathrm{CB}$ and $\mathrm{AD}$ acquired data, revised the article's intellectual content and approved the final version. GP and SDP are responsible for the integrity of this work as a whole.

\section{References}

1. Ritz E, Zeng XX, Rychlík I (2011) Clinical manifestation and natural history of diabetic nephropathy. Contrib Nephrol 170:19-27

2. Zoccali C, Kramer A, Jager KJ (2010) Chronic kidney disease and end-stage renal disease - a review produced to contribute to the report 'the status of health in the European union: towards a healthier Europe'. NDT Plus 3:213-224

3. Steinke JM, Mauer M, International Diabetic Nephropathy Study Group (2008) Lessons learned from studies of the natural history of diabetic nephropathy in young type 1 diabetic patients. Pediatr Endocrinol Rev 5(Suppl 4):958-963

4. Parving HH, Persson F, Rossing P (2015) Microalbuminuria: a parameter that has changed diabetes care. Diabetes Res Clin Pract 107:1-8

5. Currie G, McKay G, Delles C (2014) Biomarkers in diabetic nephropathy: present and future. World J Diabetes 5:763-776

6. Fineberg D, Jandeleit-Dahm KA, Cooper ME (2013) Diabetic nephropathy: diagnosis and treatment. Nat Rev Endocrinol 9:713-723

7. MacIsaac RJ, Tsalamandris C, Panagiotopoulos S, Smith TJ, McNeil KJ, Jerums G (2004) Nonalbuminuric renal insufficiency in type 2 diabetes. Diabetes Care 27:195-200

8. Kramer HJ, Nguyen QD, Curhan G, Hsu CY (2003) Renal insufficiency in the absence of albuminuria and retinopathy among adults with type 2 diabetes mellitus. JAMA 289:3273-3277

9. Thomas MC, Macisaac RJ, Jerums G et al (2009) Nonalbuminuric renal impairment in type 2 diabetic patients and in the general population (national evaluation of the frequency of renal impairment co-existing with NIDDM [NEFRON] 11). Diabetes Care 32: $1497-1502$

10. Ninomiya T, Perkovic V, de Galan BE, ADVANCE Collaborative Group et al (2009) Albuminuria and kidney function independently predict cardiovascular and renal outcomes in diabetes. J Am Soc Nephrol 20:1813-1821

11. Penno G, Solini A, Bonora E, for the Renal Insufficiency And Cardiovascular Events (RIACE) Study Group et al (2011) Clinical significance of nonalbuminuric renal impairment in type 2 diabetes. J Hypertens 29:1802-1809

12. Retnakaran R, Cull CA, Thorne KI, Adler AI, Holman RR, for the UKPDS Study Group (2006) Risk factors for renal dysfunction in type 2 diabetes: UK prospective diabetes study 74 . Diabetes 55 : 1832-1839

13. Afkarian M, Zelnick LR, Hall YN et al (2016) Clinical manifestations of kidney disease among US adults with diabetes, 1988-2014. JAMA 316:602-610

14. Caramori ML, Fioretto P, Mauer M (2003) Low glomerular filtration rate in normoalbuminuric type 1 diabetic patients: an indicator of more advanced glomerular lesions. Diabetes 52:1036-1040

15. Molitch ME, Steffes M, Sun W, for the Epidemiology of Diabetes Interventions and Complications (EDIC) Study Group et al (2010) Development and progression of renal insufficiency with and without albuminuria in adults with type 1 diabetes in the diabetes control and complications trial and the epidemiology of diabetes interventions and complications study. Diabetes Care 33:1536-1543

16. Caramori ML, Fioretto P, Mauer M (2000) The need for early predictors of diabetic nephropathy risk: is albumin excretion rate sufficient? Diabetes 49:1399-1408

17. Perkins BA, Ficociello LH, Silva KH, Finkelstein DM, Warram JH, Krolewski AS (2003) Regression of microalbuminuria in type 1 diabetes. N Engl J Med 348:2285-2293

18. de Boer IH, Rue TC, Cleary PA, Diabetes Control and Complications Trial/Epidemiology of Diabetes Interventions and Complications Study Research Group et al (2011) Long-term renal outcomes of patients with type 1 diabetes mellitus and microalbuminuria: an analysis of the diabetes control and complications trial/epidemiology of diabetes interventions and complications cohort. Arch Intern Med 171:412-420

19. MacIsaac RJ, Jerums G (2011) Diabetic kidney disease with and without albuminuria. Curr Opin Nephrol Hypertens 20:246-257

20. Marshall SM (2014) Natural history and clinical characteristics of CKD in type 1 and type 2 diabetes mellitus. Adv Chronic Kidney Dis 21:267-272

21. Stephenson J, Fuller JH, on behalf of the EURODIAB IDDM Complications Study Group (1994) Microvascular and acute complications in IDDM patients: the EURODIAB IDDM complications study. Diabetologia 37:278-285

22. International Federation of Clinical Chemistry and Laboratory Medicine (IFCC) Scientific Division, Mosca A, Goodall I et al (2007) Global standardization of glycated hemoglobin measurement: the position of the IFCC working group. Clin Chem Lab Med 45:1077-1080

23. Friedewald WT, Levy RI, Fredrickson DS (1972) Estimation of the concentration of low-density lipoprotein cholesterol in plasma, without use of the preparative ultracentrifuge. Clin Chem 18:499-502

24. Levey AS, Bosch JP, Lewis JB, Greene T, Rogers N, Roth D (1999) A more accurate method to estimate glomerular filtration rate from serum creatinine: a new prediction equation. Modification of diet in renal disease study group. Ann Intern Med 130:461-470

25. Kidney Disease: Improving Global Outcomes (KDIGO) CKD Work Group (2013) KDIGO clinical practice guideline for the evaluation and management of chronic kidney disease. Kidney Int Suppl 3:1-150

26. Wilkinson CP, Ferris FL III, Klein RE, Global Diabetic Retinopathy Project Group et al (2003) Proposed international clinical diabetic retinopathy and diabetic macular edema disease severity scales. Ophthalmology 110:1677-1682

27. Kanji JN, Anglin RE, Hunt DL, Panju A (2010) Does this patient with diabetes have large-fiber peripheral neuropathy? JAMA 303: 1526-1532

28. Prineas RJ, Crow RS, Blackburn H (1982) The Minnesota code manual of electrocardiographic findings. John Wright-PSG, Boston

29. Costacou T, Ellis D, Fried L, Orchard TJ (2007) Sequence of progression of albuminuria and decreased GFR in persons with type 1 diabetes: a cohort study. Am J Kidney Dis 50:721-732

30. Hill CJ, Cardwell CR, Patterson CC et al (2014) Chronic kidney disease and diabetes in the national health service: a cross-sectional survey of the UK national diabetes audit. Diabet Med 31:448-454

31. Thorn LM, Gordin D, Harjutsalo V, FinnDiane Study Group et al (2015) The presence and consequence of nonalbuminuric chronic kidney disease in patients with type 1 diabetes. Diabetes Care 38: 2128-2133

32. Zerbini G, Bonfanti R, Meschi F et al (2006) Persistent renal hypertrophy and faster decline of glomerular filtration rate precede the development of microalbuminuria in type 1 diabetes. Diabetes 55: 2620-2625

33. Perkins BA, Ficociello LH, Ostrander BE et al (2007) Microalbuminuria and the risk for early progressive renal function decline in type 1 diabetes. J Am Soc Nephrol 18:1353-1361 
34. Perkins BA, Krolewski AS (2009) Early nephropathy in type 1 diabetes: the importance of early renal function decline. Curr Opin Nephrol Hypertens 18:233-240

35. Krolewski AS, Niewczas MA, Skupien J et al (2014) Early progressive renal decline precedes the onset of microalbuminuria and its progression to macroalbuminuria. Diabetes Care 37:226-234

36. Perkins BA, Ficociello LH, Roshan B, Warram JH, Krolewski AS (2010) In patients with type 1 diabetes and new-onset microalbuminuria the development of advanced chronic kidney disease may not require progression to proteinuria. Kidney Int 77: $57-64$

37. Krolewski AS, Gohda T, Niewczas MA (2014) Progressive renal decline as the major feature of diabetic nephropathy in type 1 diabetes. Clin Exp Nephrol 18:571-583

38. Krolewski AS (2015) Progressive renal decline: the new paradigm of diabetic nephropathy in type 1 diabetes. Diabetes Care 38:954 962

39. MacIsaac RJ, Panagiotopoulos S, McNeil KJ et al (2006) Is nonalbuminuric renal insufficiency in type 2 diabetes related to an increase in intrarenal vascular disease? Diabetes Care 29:1560 1566

40. Thelwall PE, Taylor R, Marshall SM (2011) Non-invasive investigation of kidney disease in type 1 diabetes by magnetic resonance imaging. Diabetologia 54:2421-2429

41. Ficociello LH, Rosolowsky ET, Niewczas MA et al (2010) Highnormal serum uric acid increases risk of early progressive renal function loss in type 1 diabetes: results of a 6-year follow-up. Diabetes Care 33:1337-1343
42. Barutta F, Bruno G, Grimaldi S, Gruden G (2015) Inflammation in diabetic nephropathy: moving toward clinical biomarkers and targets for treatment. Endocrine 48:730-742

43. Reidy K, Kang HM, Hostetter T, Susztak K (2014) Molecular mechanisms of diabetic kidney disease. J Clin Invest 124:23332340

44. Klein RL, Hunter SJ, Jenkins AJ, DCCT/ECIC STUDY GROUP et al (2003) Fibrinogen is a marker for nephropathy and peripheral vascular disease in type 1 diabetes: studies of plasma fibrinogen and fibrinogen gene polymorphism in the DCCT/EDIC cohort. Diabetes Care 26:1439-1448

45. Koenig G, Seneff S (2015) Gamma-glutamyltransferase: a predictive biomarker of cellular antioxidant inadequacy and disease risk. Dis Markers 2015:818570

46. Lee DH, Jacobs DR Jr, Gross M, Steffes M (2005) Serum gammaglutamyltransferase was differently associated with microalbuminuria by status of hypertension or diabetes: the coronary artery risk development in young adults (CARDIA) study. Clin Chem 51:1185-1191

47. Targher G (2010) Elevated serum gamma-glutamyltransferase activity is associated with increased risk of mortality, incident type 2 diabetes, cardiovascular events, chronic kidney disease and cancer a narrative review. Clin Chem Lab Med 48:147-157

48. Giorgino F, Laviola L, Cavallo Perin P, Solnica B, Fuller J, Chaturvedi N (2004) Factors associated with progression to macroalbuminuria in microalbuminuric type 1 diabetic patients: the EURODIAB prospective complications study. Diabetologia 47:1020-1028 